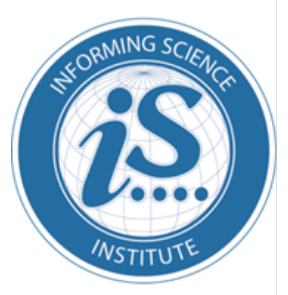

Proceedings of the Informing Science + Information Technology Education Conference

An Official Publication

of the Informing Science Institute

InformingScience.org

InformingScience.org/Publications

June 30 - July 4 2019, Jerusalem, Israel

\title{
A BROADER LOOK AT A STUDENT NEWSPAPER UNDER DisRUPTIVE CHANGES
}

Minh Huynh*

Nicholas Walsh

Scott McDonald

Corresponding author*
Southeastern Louisiana University, $\quad$ minh.huynh@selu.edu Hammond, LA USA

Southeastern Louisiana University, Hammond, LA USA

RMIT University, Ho Chi Minh City, $\quad$ scott.mcdonald@,rmit.edu.vn Vietnam

\section{ABSTRACT}

Aim/Purpose

Background

Methodology

Contribution

Findings

Recommendations for Practitioners
This paper focuses on student newspapers in the midst of digital transformation and the impact this has on their future survival.

The ramification of digital transformation on commercial newspapers is not new, but looking at it from a big picture helped to us to connect to what has been happening with student newspapers across the United States.

Through a limited review of selected student newspapers across the country, this paper attempted to identify key challenges, trends, and best practices to determine the current as well as future state of this media model.

The knowledge gained was then used to inform a transition of a specific student newspaper to cope with its own challenges and to share this condition with other schools around the nation.

Due to the digital transformation, the traditional student newspapers have been disrupted and are going through the transition into digital platforms similar to those in the commercial newspapers. Yet, the value of the content is still important.

Rapidly advanced technology transform student newspapers into a real-time, highly customized, personal, rich with multimedia format. This means the newspapers must be able to reach where their readers are and deliver what their readers ask for.

Accepting Editor: Eli Cohen | Received: October 1, 2018 | Revised: December 13, December 29, 2018, January 8,2019 | Accepted: January 9, 2019.

Cite as: Huynh, M., Walsh, N., \& McDonald, S.. (2019). A broader look at a student newspaper under disruptive changes. Proceedings of the Informing Science and Information Technology Education Conference, Jerusalem, Israel, pp. 335-350. Santa Rosa, CA: Informing Science Institute. https://doi.org/10.28945/4211

(CC BY-NC 4.0) This article is licensed to you under a Creative Commons Attribution-NonCommercial 4.0 International License. When you copy and redistribute this paper in full or in part, you need to provide proper attribution to it to ensure that others can later locate this work (and to ensure that others do not accuse you of plagiarism). You may (and we encourage you to) adapt, remix, transform, and build upon the material for any non-commercial purposes. This license does not permit you to use this material for commercial purposes. 
Recommendation The transition of newspapers to be more digitized calls for more studies on the for Researchers rise of new generation of readership, the relentless changes in technology, the search for a sustainable revenue model for e-newspaper, as well as issues in selfgenerated journalism.

Impact on Society As more people gain access to portable digital devices, the desire for hard copy newspapers that report yesterday's news is rapidly decreasing. In today's world, the news is instantaneous and the lag time between the event and it being reported is sometimes mere seconds.

Future Research Research on "fake news" is important as newspapers become more digitalized. Keywords student newspapers, digital media, hybrid approach, digital transformation

\section{INTRODUCTION}

Digital transformation in a simple term refers to a fundamental shift in the way that an organization creates and delivers value to its customers. More specifically, George Westerman, principal research scientist with the MIT Sloan Initiative on Digital Economy, characterized digital transformation as a radical rethinking of how an organization uses technology, people and processes to radically change business performance (Boulton, 2018). As the world continues to digitize, it is difficult not to feel the impact of digital transformation.

In this paper, we explore one such impact that threatens the existence of traditional print newspapers. Since the commercialization of the Web almost 30 years ago, so much change has occurred in the long-established world of printed newspapers. In the United States in particular, it is of no surprise that many newspapers are struggling and fighting an uphill battle including even those stalwart newspapers such as The Washington Post, The New York Times (TNYT), and The Wall Street Journal. These leading newspapers experienced not just the decline in their circulation but also the threat from digital "native" media platforms such as Buzzfeed and The Huffington Post (Harvard Business School (HBS), 2015; 2018). The pressure has grown as more readers shift from broad national/global stories published once a day to a 24 -hour news cycle that can be customized to individual preference. These days, news is expected to be disseminated rapidly and digested quickly at anytime and anywhere through mobile devices (HBS, 2015). Failure to do so would result in a direct hit at the bottom line as reflected in TNYT's financials: in 2003, TNYT generated $\$ 551 \mathrm{M}$ in net operating profit and in 2014 , the figure was down to $\$ 92 \mathrm{M}$. This is an alarming call not only for TNYT but also other newspapers as well (HBS, 2015). The impact of digital transformation on commercial newspapers is not a new phenomenon. The late 80's shows a start of decline in circulation of print newspapers. However, such an impact on student newspapers follows only in recent years and not much is known in this transition. Is the impact on student newspapers similar to commercial newspapers? What changes have taken place in student newspapers? How do student newspapers across the U.S. cope with tough challenges in the environment of endless upheaval in technology? What can be done with changing reader habits and growing use of social digital media? What lessons can a specific student newspaper at a regional public university draw? These questions are the reasons for this paper. Our effort to look at these questions is not to come up with solutions or to prove or disprove their solutions through a comprehensive research. Instead, we want to explore these questions and understand them through a more qualitative approach. We endeavor to review the literature, learn the best practices, and use the knowledge gained to inform us in the direction for the transition of our own student newspaper.

Specifically, our paper is organized as follows. After the introduction, the paper discusses the approach that we undertook to examine the challenges facing our own student newspaper at Southeastern Louisiana University. In this first section, we provide the basic justification of our approach as a case study. To establish the backdrop of a larger context, the next section describes the big picture of the print newspaper industry and highlights the trends. Then, we present a limited review of student 
newspapers in the context of commercial newspapers. Here, we review selected newspapers to learn of their best practices. Our primary interest is in what changes have been made at several college and university newspapers around the country in response to the impact of the digital transformation. Based on this limited review, we attempt to pinpoint major trends that have emerged from the changes. We also compare the approaches deployed by student newspapers at these colleges/universities and those of commercial newspapers. Next, we use the insights gained from our review to look closely at how our student newspaper as well as others might respond to these trends and what could be learned from the best practices by student newspapers across the U.S. Finally, we provide a summary and offer practical implications for those involved with student newspapers on campus. We end the paper with our acknowledgement of the limitations in the paper and share our thoughts for the direction of future study.

\section{OUR STUDY APPROACH}

As we mentioned in the introduction, we did not conduct this study using a comprehensive and quantitative research because we did not intend to propose any new solution or to prove or disprove existing solutions to the challenges facing student newspapers. For our purpose and need, we wanted to understand the challenges that our student newspaper faced and what we could do to address them. Based on this, we chose a case study as the basic approach for our inquiry. As Merriam (1998) put it, "research is, after all, producing knowledge about the world..." There are different approaches to research, but the fundamental goal is to seek knowledge and to inform practice. Some approaches are positivistic and hence more quantitative because their design and method stress on important aspects of measurable constructs, validity, and reliability. Other approaches are interpretive and hence more qualitative. These approaches view knowledge as something to be constructed rather than discovered (Stake, 1995, p.99). In this paper, we followed the interpretive tradition. Our attempt was to review the existing phenomenon, look at the big picture, and then closely examine a specific area of our interest. In our case, instead of randomly choosing a sample of student newspapers, we referred to the literature to point us to selected student newspapers to review. The student newspapers that we chose were not ad hoc, they were selected because they were reported in the literature and hence reflected some unique or significant aspects in the context of our study. From our review of selected student newspapers and their best practices, we extracted the insights and drew practical implications. Our assumption was that reality is not an objective entity, but rather it is an interpretation resulted from reading and observing of the phenomenon. Therefore, our case study approach is not to prove or to disprove a hypothesis but to understand the meaning or make sense of the phenomenon. As Merriam (1998) put it, the final product of this type of study is yet another interpretation by the researcher of others' views filtered through his or her own (Merriam, 1998, p. 22).

\section{THE BIG PICTURE - THE PRINT NEWSPAPER INDUSTRY}

In this section, we want to take a broader look at the drastic changes in the traditional print newspaper industry. Figure 1 shows that paid circulation of daily newspapers in the US had steadily declined during the period from 1985 to 2016. 


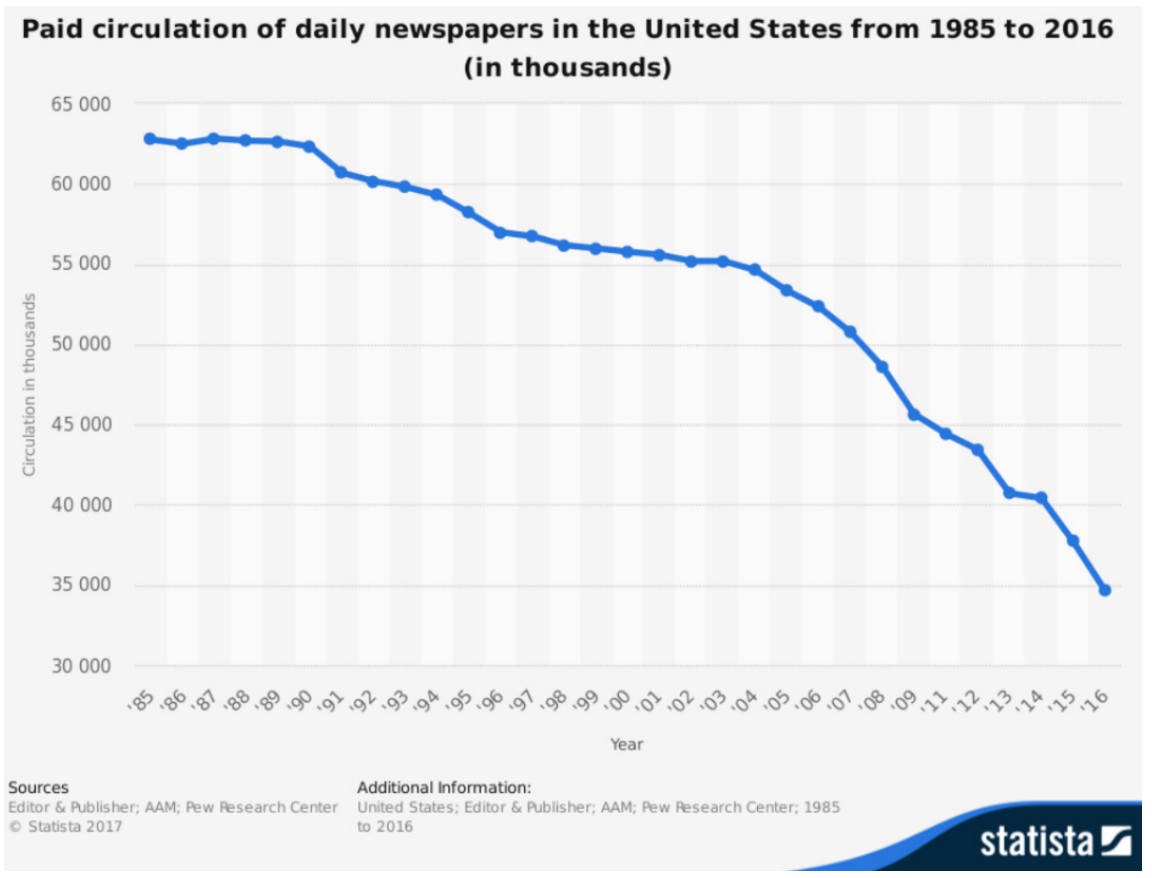

Figure 1: Decline in circulation of newspapers over the years 1985-2016

This decline started much earlier. Since the 50's, as more people got their news from TV, the growth had been stagnant. With the arrival of the Web in 90s, it quickly became the preferred source of news for the average reader. As a result, the shifts from broad national/global news published once a day to a 24-hour news cycle became inevitable. Furthermore, since news from the Web was available mostly for free, the paywalls had consistently been a difficult hurdle for consumers to get over (HBS, 2018).

Other pressures came from competition as shown in Figure 2. The rise of digital "native media platforms such as the Huffington Post, Buzzfeed intensified the competitive dynamics in news industry" (HBS, 2018). These new players were often better equipped to capture value in the digital age. Many of them were able to offer free content and hence the switching costs were low for consumers.

Finally, the impact of the decline in circulation coupled with the increase in the competition was indicative by the evidence of the significant decrease in advertising revenue and the lack of growth in circulation revenue. Figure 3 captured this trend although the numbers were specifically related to TNYT and The Wall Street Journal.

As pointed out above, national legacy printed-press stalwarts including The Wall Street Journal, The New York Times, and The Washington Post have been at a crossroads. When sales of their print newspapers began to plummet, they were forced to rewrite their business plans and make the transition into a digital-first approach. Some ventured into a hybrid approach by offering both print and digital formats. To understand beneath the surface of these declines, we chose an e-business model to guide us in our interpretation of the emerging trends. 


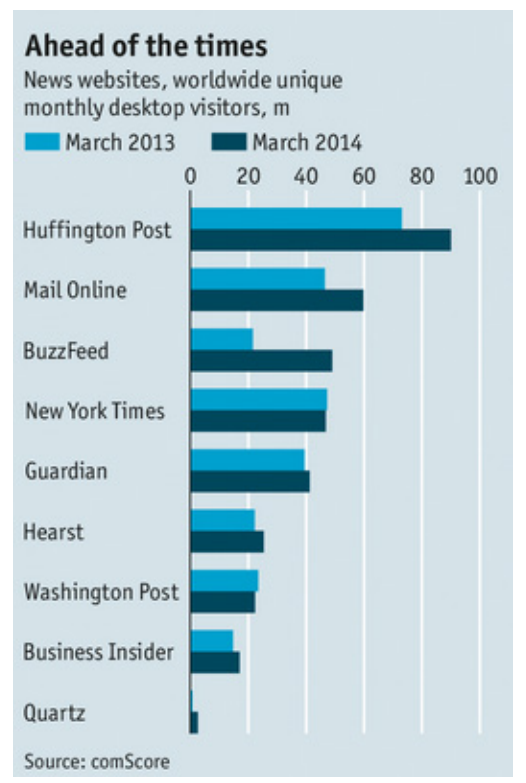

Figure 2: The rise of digital "native media platforms"

\section{Signs of the Times}
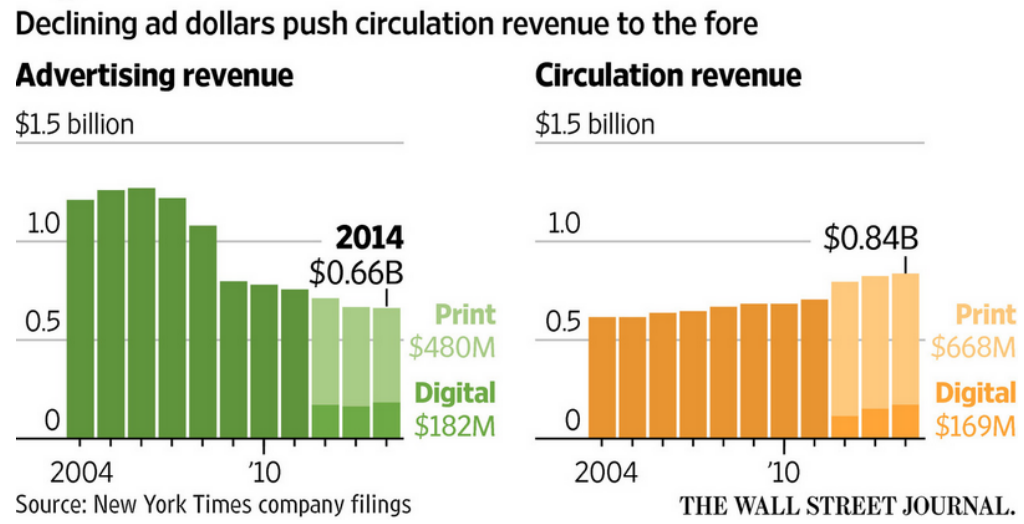

Figure 3: Decline in both ad and circulation revenues

There have been several digital e-business models developed since the turn of the century with a focus on three critical components: the content which in this case is information, the structure which connects the content to the stakeholders, and the governance of the delivery of the content which controls the flow of information. One concern of digital e-business users is DRMS (Digital Rights Management Systems) and the potential to protect their online content. The industry is still waiting for the appropriate tools that may add an element of security regarding content delivered in a platform that is currently plagued by online hackers and data theft (Amit \& Zott, 2001; Fetscherin \& Knolmayer, 2004; Taylor, Fritsch \& Liederbach, 2014). Although the content is the focus of many online publications, it appears to be the least understood aspect of many e-business models (Alt \& Zimmerman, 2001; Fetscherin \& Knolmayer, 2004; Rappa, 2001). The content has evolved from being the sole possession of "the journalist" to a mix of collaborative efforts between these traditional contributors and the community of "citizen journalists" sharing today's Web 2.0 platform. Many newspapers across the nation, including university and college editions, have made the transition to digitalization in one form or another and continue to evolve and adjust the mix between electronic 
and paper printed publications struggling to determine the ideal model in this era of unproven successes (Karimi \& Walter, 2015). The last component regarding the governance of the delivery is in the hands of the publication's gatekeepers. With the uncertain future of Net Neutrality issues looming on the horizon, the models used today by media outlets around the nation may be subject to revisions in the monetization of content collection and content delivery. There are at least five collective drivers of this change currently making their presence felt in the industry: millenialization, globalization, platformization, business virtualization, and prosumerization (Gimpel \& Westerman, 2012). The effects of these changes predominantly impact the CIME industries (Communications, Information, Media, and Entertainment) which include the college campus newspaper. The future of the print newspaper industry is concerning to those intimately involved and is trending towards the same path that has disrupted other industries taken down by innovation, and some already foresee the ultimate collapse of the industry as we know it today (American Press Institute (API), 2006; Dumpala, 2009; Karimi \& Walter, 2015; Pew Research Center, 2013).

Despite many differences between student newspapers and commercial newspapers, when we viewed both from an e-business model perspective, we could identify some critical components that they both shared. We could also see the broader factors that were affecting the industry. Such a view could help us understand deeper the impacts and the direction of the industry. In turn, these insights could provide us the needed guidance in making the correct responses and appropriate adjustments to help student newspapers ride the wave of changes.

\section{A LIMITED REVIEW OF SELECTED STUDENT NEWSPAPERS ACROSS THE COUNTRY}

The previous section highlighted key trends observed in commercial newspapers over the years. In this section, we turn out focus to student newspapers. We take a closer look at the disruptive changes at a number of student newspapers across different campuses in the U.S. Student newspapers have been for many years, a daily or weekly publishing ritual throughout higher education in every corner of the globe. Students would grab a copy at one of the many newsstands and newspaper racks as they navigated around the campus on their way to or from classes. On today's campuses around the country, this tradition is changing. We are witnessing an unprecedented shift in the way that student newspapers are produced, delivered, and received. At some schools, the shift has taken place in a very disruptive way. The case in point is what happened to the University of North Carolina's student newspaper on Tuesday 8/30/2016. For the first time in its 123-year-old history, the Daily Tar Heel was not published as a print edition on Tuesday (Kramer, 2016).

As mentioned above, the Daily Tar Heel despite its long history, had to drop a day of the print edition to focus more on digital media. This is not an isolated instance. In fact, student newspapers at other major universities had taken similar measures. Included in this group of schools are the University of Wisconsin-Madison, the University of South Carolina, the University of Pennsylvania, Cornell University, the University of Maryland, the University of Georgia, the University of Oregon, Columbia University, the University of California-Berkeley, Syracuse University, the University of Nebraska, Duke University, Arizona State University, University of Arizona, University of Minnesota, University of Utah, the University of Texas-Austin, and the University of Kansas. All of them had rolled back their print editions (Kramer, 2016). They cut down on both the number of newspapers they printed and the frequency with which they printed them. For instance, the University of Arizona, University of Minnesota and the University of Oregon dropped their circulation from daily, to 2 or 3 days per week (Ascarelli, 2014).

Another approach that we observed is that many of the major student newspapers offered a mobile app as a mechanism to direct students towards their digital presence. After trying several of these apps ourselves, we found some underlying similarities in the key features and functionalities. A close examination of student newspaper apps from large newspapers at schools like Western Kentucky, Stanford and NYU revealed that they had likely used the same mobile app development platform in 
terms of the features and functionalities. Beyond the variations in color, theme, and local content, these design templates were quite similar in navigation setup, icons, and functionalities. Hence, the key distinction among these apps rest on the content customized and designed for a specific college/university and not much in the way of functionalities. Because each school catered to different needs, its student newspaper had to incorporate certain university-specific content into its app. For instance, at Louisiana State University (LSU), features such as bus schedules, campus updates, and links to the college radio station were part of its student newspaper mobile app. Figure 4 shows the screen captures of student newspaper apps from Stanford and LSU. The figure also showed the similarities between the two apps with features like news, sports, and opinion.

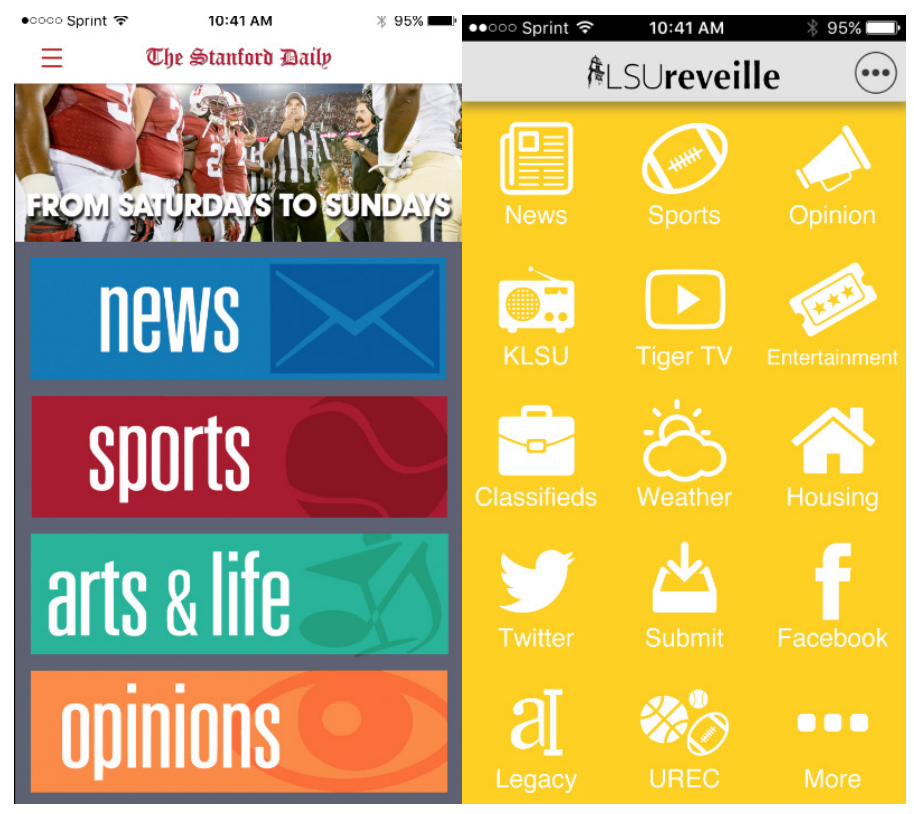

Figure 4: Examples of the student newspaper app interface

One of the interesting approaches that we observed at Stanford University's student newspaper was its effort to engage students in mass customization. Although mass customization is one of the commonly-recognized capabilities in digital media, it is almost impossible to get mass customization through traditional print media. Stanford University used a daily newsletter that went out to students' emails with national and campus news as well as a notification function as shown in Figure 5. This simple implementation allowed Stanford students not only to sign up for the news but also to customize and personalize the content. In other words, students could choose what was most interesting to them and received alerts when there were updates in those categories (http://www.stanforddaily.com/).

Another approach that we observed was quite promising but not yet fully deployed. It was based on the concept of user-generated content, which was quite popular in the realm of current social media. The idea was to allow users to contribute content, to promote users' engagement on the content, and to facilitate and proliferate user-generated news. We found that The Daily Reveille at LSU to some extent utilized this approach, but it was not completely functional at the time of this writing. Allowing users to upload content was more complex than creating a forum for discussion, but the possibilities were much greater. Not only did this provide for more diverse and unique content, but it also took much of the burden off the newspaper staff to be the sole creators of the content. At some of the smaller newspapers, including The Lion's Roar at SELU, there simply was not enough manpower to generate new articles every day. However, allowing users to generate their own information gave the newspaper the ability to offer new subject matter every day and gave the students a perceived notion of belonging to the community and thus the school. In such a case, the newspaper staff could then act as facilitators, curators or editors of content. They were responsible for funneling the up- 
loaded content into the appropriate categories and making sure that it was the quality of news that they deemed important enough to publish.

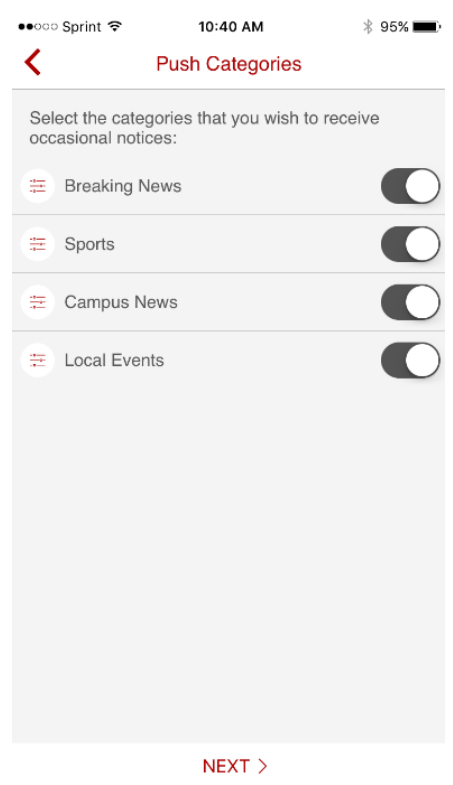

Figure 5: Example of a feature to allow mass customization. (Adopted from http://www.stanforddaily.com/)

A number of schools had adopted the hybrid approach with both a print edition as well as a digital edition. For instance, LSU's newspaper, The Daily Reveille, had been a daily newspaper since its inception in 1897. However, in the Spring of 2017, they switched their publication schedule to once per week and decreased their circulation to 7,000 editions for a campus of over 32,000 staff and students. The majority of their content was currently published on their website, LSUNow, which was updated daily with news headlines, sports, and opinions. LSUNow also did a good job of incorporating social media into its site and opened revenue streams by allowing companies to post their Twitter streams on the homepage (http://www.lsunow.com/). Figure 6 shows a snapshot of LSUNow website with Twitter streams.

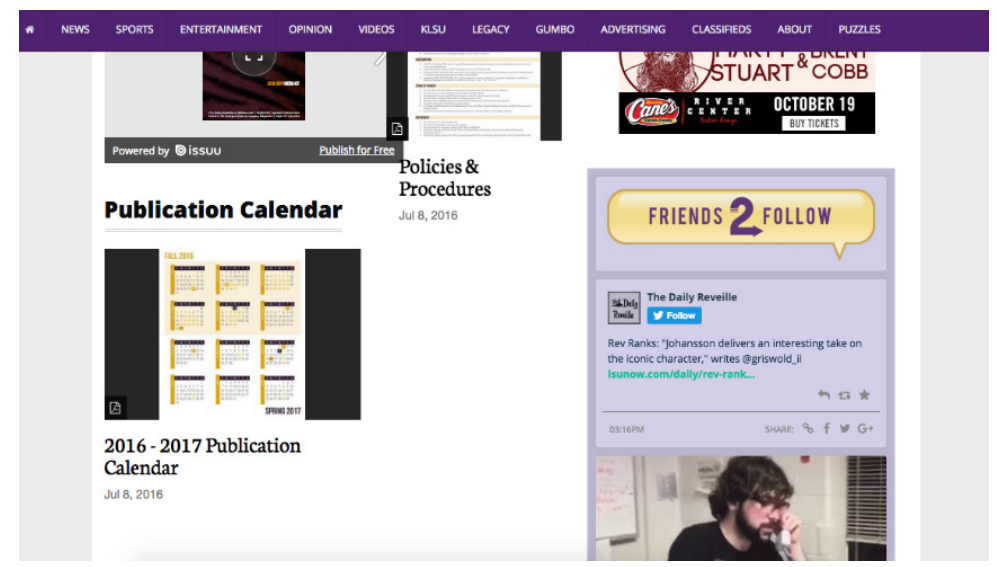

Figure 6: A snapshot of a page on LSUNow website

LSU was not alone in the hybrid approach. Stanford was another school that embraced this approach to combine both the traditional value of print media and the digitalization of it with the power of mass customization. It offered a promising model for how to serve both types of readers. The school still offered a hard copy of their weekly edition at over 900 locations on campus and throughout the 
community, but they made sure to only print as many newspapers as they needed. As mentioned in Figure 5 above, their other options for those who still wanted their news delivered to them daily was their newsletter service which sent out a new edition to the user's email 'inbox' at 6 a.m. daily Monday-Friday. Furthermore, they offered the convenience of choosing which type of newsletter would most interest the reader. There was a daily that focused on sports and culture-related content, and a different one for those interested in news headlines. This format was ideal for a large population and offered opportunities for further customization and growth. Figure 7 shows the feature supporting a subscription approach.

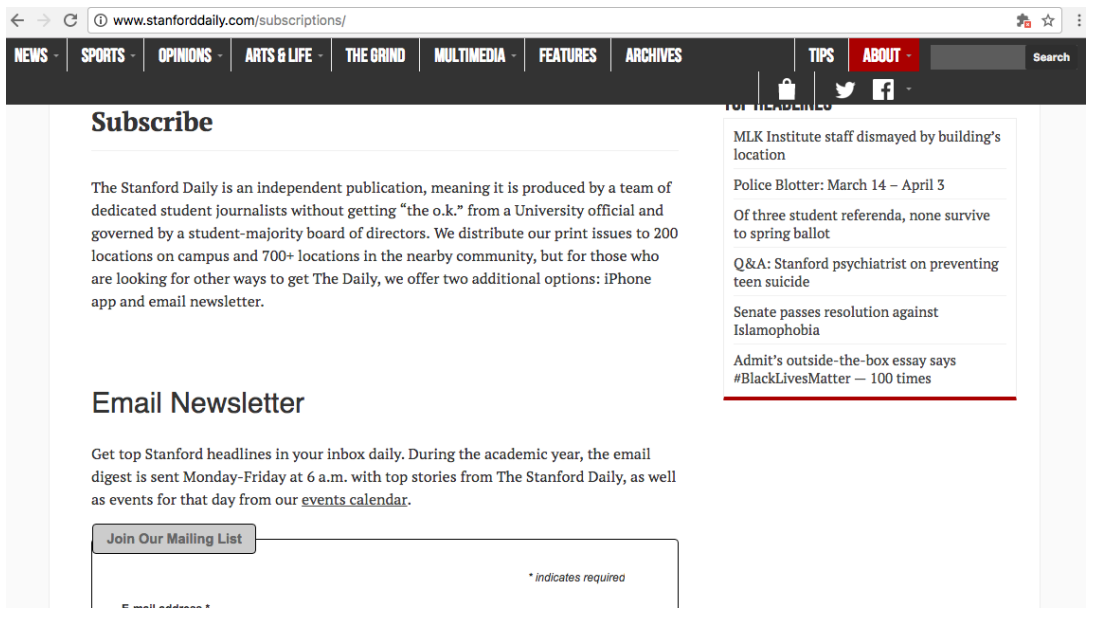

Figure 7: Examples of a subscription approach used at Stanford. (Adopted from http://www.stanforddaily.com/)

One of the more drastic measures that some student newspapers took was the complete substitution of the print edition with the digital edition. For instance, Franklin \& Marshall College lost so much money on the print version of their newspaper that they couldn't afford to pay the staff. The decision was made to change to an all-digital platform that sent a PDF version of the newspaper to their students and staff every week (Ascarelli, 2014). The savings was quite significant. The traditional newspaper was costing $\$ 800$ per week to print 500 copies of a 12-page newsprint publication that included four full-color pages. Now, with the switch to a digital platform, the operational budget was only $\$ 300$ for a whole year, which covered web hosting, office supplies, and promotional activities (Sweeney, 2015).

\section{IDENTIFYINGMAJOR TRENDS}

The limited review of selected student newspapers across the U.S. and the challenges facing The Lion's Roar all seem to point to the reality--that is, student newspapers are facing swift changes. With dwindling funding from schools, a different generation of readership, and the pervasiveness of digital technology such as social media, student newspapers cannot operate their businesses as usual. Their print edition is simply not enough and less attractive to today's readers. Despite the wave of changes, there has not yet emerged a clear model that can guide student newspapers to sail through the rough transition to digital media. From our review of selected student newspapers, we identified the following trends. Recognizing and responding to these trends is the first step in deriving a working model.

The first trend is that the print edition should not be the only platform in today's world. In other words, the traditional way of producing, publishing, and distributing the print newspapers is not sustainable. The cost is rising while the source of funding is shrinking. The trend is clearly visible in the responses by a number of schools. Most of them had either reduced the number of prints or the frequency of prints or done both. Going a step further, some had eliminated the print edition and 
replaced it with a digital edition as seen in the case of the student newspaper at Franklin \& Marshall College.

This led us to the second trend in which we observed the emergence of different digital edition approaches. One approach was to replace print edition with a digital edition in the popular PDF format as implemented at Franklin \& Marshall College. Since the PDF (Portable Document Format) format is cross-platform, this kind of digital edition could be posted on the web, sent over email, tagged and shared on any social media platform. While the PDF format is good for document sharing, it is not the ideal platform for accessing, reading, and navigating content like a newspaper. Rather than eliminating print edition, another approach that several schools chose is to use a hybrid concept. The idea was to combine the best of both worlds. The hybrid approach continued to operate on the traditional value of print media and at the same time make use of the power of digital media. Schools like Stanford and LSU tried and seemed to do quite well with this hybrid approach. The challenge here was how to balance between print edition and digital edition so that they would be complementary to one another rather than competing and eventually cannibalizing one another. In terms of going digital, it was more complex because at this point there was not one channel but multi-channels that the digital edition must utilize to reach out to its readers. Some schools posted their student newspapers on the web-like LSUNow. Others such as The Lion's Roar used social media like Facebook to distribute their newspaper content.

Many schools offered mobile apps to access their student newspapers. These apps in general offered functionalities that were quite similar because all these apps were most likely built and designed on the same development platform. Although the main purpose of these apps was to provide news articles to its readers, their design also included other useful features and functionalities relevant to specific schools. With existing digital technology, it was possible for student newspapers to offer mass customization. Students could pick and choose what content they wanted to read. Stanford was leading the way on this path. This advantage made it possible to push the relevant and desired content to the readers in real-time.

Another interesting trend that potentially capitalized the power of Web 2.0 was for student newspapers to engage students themselves as news contributors. Being able to tap into this great resource could potentially make the news much richer, more relevant, and with updates in real-time. Usergenerated content could be more feasible and suitable because the generation of today's students were accustomed to social media and mobile smartphones.

\section{SOME SIMILARITIES IN THE TRENDS BETWEEN COMMERCIAL NEWSPAPERS AND STUDENT NEWSPAPERS}

In-depth comparing and analyzing between student newspapers and commercial newspapers was beyond the scope of this paper. As we looked at the commercial newspapers in the big picture and explored a sample of student newspapers, we noticed some parallels between student newspapers and national commercial newspapers. The challenges faced by student newspapers were indeed quite like those faced by commercial newspapers. For instance, when sales of their print newspapers began to plummet, commercial newspapers were forced to rewrite their business plans and make the transition into a digital-first approach. Some ventured into a hybrid approach like that of student newspapers. They offered both print and digital formats. This was quite like the reactions that many student newspapers had taken. Although the overall aggregated circulation of printed newspapers in the US declined by slightly more than $21 \%$ and the number of newspaper titles dropped by $9.5 \%$ between the years 1995-2009, this was not as dramatic an impact as some may have originally feared (Cho, Smith \& Zentner, 2016). We did observe a similar trend in which circulation of the print edition student newspaper had dropped over the years.

Despite many differences between student newspapers and commercial newspapers, when we viewed them from an e-business model perspective, we could identify some critical components that they 
both shared. We could also see the broader factors that impacted the industry. Such a view helped us understand deeper the impact and the direction of the industry. Based on these, we identify major trends in student newspapers and examined them in the context of the newspaper industry to derive further insights. In turn, these insights provided us the needed guidance in making the correct responses and appropriate adjustments to help our own student newspaper to ride the wave of changes.

\section{Our specific case - The Lion's roar}

The Lion's Roar is the name of the official newspaper of the students at Southeastern Louisiana University (SELU). The paper is printed and distributed on Tuesdays. During the regular semester, it is published weekly. Students play a major role in the process of planning, writing, designing, and producing the weekly newspaper. It has been in continuous publication since 1937.

In recent years, The Lion's Roar has faced many challenges due to internal constraints as well as external pressure. Like other school newspapers, the most visible and immediate threat is the financial challenge that The Lion's Roar faces. Its production cost is steadily increasing while its revenue and funding are significantly shrinking. To reduce the production cost, the paper is faced with the decision of whether to reduce its print circulation. Yet, the reduction in print circulation means less revenue from printed advertisements. At the same time, due to the severe budget cuts from the state over several consecutive years, the funding to support the paper has been greatly reduced. On top of the financial limitation, The Lion's Roar is facing a new generation of readership that has grown up with social media and smartphones. The traditional approach of delivering news in a print copy does not seem to meet the demand of its changing readership. Ultimately, The Lion's Roar must make changes not only to overcome its financial constraints but more importantly to adjust itself to remain relevant among today's students and to thrive in an increasingly digitized environment. The key questions are the following: What strategic changes need to be made at The Lion's Roar and what direction should it take to transition into the era of social, mobile, and local news platforms?

\section{Understanding the current practice and identifying an emerging model}

As we started looking deeper for possible answers to these key questions, we discovered that The Lion's Roar was not alone in its predicament. In fact, we discovered that many campuses around the country had encountered similar issues and several had already taken different measures to deal with these challenges. Based on all these trends in the previous sections, we attempted to synthesize a general working model for student newspapers. This synthesis was based on our fundamental understanding of a push vs. pull model in supply chain management systems. Like the push-based model and the pull-based model in supply chain management systems, we observed that the existing model for student newspapers at most schools was a push-based model. In a push-based model, products were produced based on forecasts of demand and were pushed to customers; whereas, in a pullbased model, it was the actual customer purchase that triggered events in the supply chain. Taking this concept and applying it in the context of student newspapers, we noted that for years, student newspapers had traditionally operated in the push-based model. Newspapers were printed, packaged, delivered, and distributed to readers. Newspapers were the only channel where students could get their news. Yet, with the pervasive use of digital technology such as social media and smartphones, there were other ways to get news in real time. The news came to readers not only in text but also in video and audio format. More importantly, today's readers wanted access to news at any time and in any place. Furthermore, they wanted the ability to choose what they wanted to read. Such demands made print edition less dominating as it once was. It was just a matter of time when the disruption spread so quickly and widely that print edition of student newspapers across the country would eventually be pushed aside and become obsolete due to drastic changes in the environment.

As we observed from the previous sections, some schools had begun tapping into the power of digital media by offering mass customization, user-generated news, and to some extent push the content 
to the readers. This is what we characterized as a pull-based model in student newspapers. By letting readers customize what they choose to read when they want to read, and how they prefer to read, the newspaper is capable of producing, delivering, and distributing just-in-time content for its readers. This is not easy to achieve, but we have seen some of the schools' attempt to do so with various success.

Based on what we observed around the country and what we experienced at The Lion's Roar, we propose that the future model for student newspapers consists of both pull and push-based models. Since there are always readers who do not want to change or are late adopters of a new format, the push-based model remains for them. The print edition is still important to this segment of readers. To save costs, a digital version of the print edition can be posted on the web or it can be distributed via a mobile app. However, the future student newspapers should pursue not only the current pushbased model but also combine it with the pull-based model to fully capitalize the power of digital media.

Despite the disruption brought by a rapidly changing technology, we do not believe that jumping on the technology bandwagon is sufficient to navigate through the wave of changes. As pointed out earlier, it is important to view the challenges, the trends and the emerging model facing student newspapers from an e-business perspective. We need to look at all three critical components: the content, the structure, and the governance of the delivery of the content. All three components are in place and work together effectively for student newspapers to survive and thrive. In the newspaper business, the value of content is still important. What draws readers is the high-quality content. We need the structure that connects the content to the readers. In the era of digital media, we need to expand our structure to integrate multiple channels so that we can go wherever our readers are. Finally, the new technology brings new capabilities. With Web 2.0 and soon 3.0, the governance of the delivery of the content should not be just the staff in the newsroom or the so-called publication's gatekeepers. We need to take tap into the community of "citizen journalists".

\section{CONCLUSION}

In this paper, we looked at the case of student newspapers in the context of the whole newspaper industry and with implications and applications for our specific student newspaper on campus. We started the paper with our approach to the study. Next, we provided the big picture of the newspaper industry. Since our scope was not on providing an exhaustive review of the industry, we highlighted the major trends that had impacted and even disrupted the traditional newspaper industry. Then, we discussed these trends through the lens of the e-business model. We attempted to make sense of the changes in the industry by discussing specifically on the three components: the content, the structure, and the governance of the content. After viewing the newspaper industry from a big picture standpoint, we narrowed our scope to student newspapers. We examined a selected sample of student newspapers from across the country. The review was limited because we focused mainly on those student newspapers that had appeared in the news or related literature. By doing so, we could reflect to some extent, swift changes that a typical student newspaper in the U.S. was facing. From the review, we extracted the major trends and identified aspects that we could apply to our specific context- the Lion's Roar, the student newspaper at our university.

From our specific context, the main challenge that SELU's student-run newspaper, The Lion's Roar, was facing is one that reflects the need for changes. As more people gain access to portable digital devices, the desire for hard-copy newspapers that report yesterday's news is rapidly decreasing. In today's world, the news is instantaneous and the lag-time between the event and it being reported is sometimes mere seconds. This wave of changes in how news is reported and received has led to newspapers being forced to radically alter their traditional methods of delivery that have sustained them throughout their lengthy printing history. The news outlets who can make these adjustments on the fly and as they happen without sacrificing quality, find themselves as the vanguards and thus leading the way into this increasingly digital era. 
Today's rapidly advancing technology can completely transform student newspapers into a real-time, highly customized, personal, rich with multimedia format that are accessible at any time and in any place. This means the newspapers must be able to reach where their readers are and deliver what their readers ask for.

\section{PRACTICAL IMPLICATIONS}

Because newspapers rely on technology, they cannot afford to ignore the new and emerging technology even though some technology can be disruptive. As we discussed earlier, not only student newspapers, but also commercial newspapers are facing tremendous challenges because they are operating in the environment of endless upheaval in technology. Yet, it is risky for newspaper formats to be driven solely by technology. It is important to retain a broader view of the challenges from an ebusiness model's perspective. We need to look at all three critical components: the content, the structure, and the governance of the delivery of the content.

Therefore, we recommended for The Lion's Roar as well as other student newspapers to not focus solely on technology as the solution for their challenges. Student newspapers should view the disruptive changes not as a threat but as an opportunity to be embraced, as well as to advance and to adjust. We suggested that the key to ride above the wave of changes is the ability to learn and to see things from a big picture. One way to achieve this is to view the challenges because of digital transformation not from a technological standpoint but from an e-business model point of view.

Another important implication is the ability to deliver truly quality content. When a student newspaper can provide truly compelling contents on the right media, it can engage students to interact and contribute to its content. Then, with the appropriate use of digital technology, it can give students better choices regarding their desired contents and allow them to access such contents at any time and from any place.

\section{LIMITATIONS AND FUTURE STUDY}

In this paper, we set out to look at the challenges facing our own student newspaper and explore ways to deal with these challenges. We reviewed the impact of digital transformation on commercial newspaper industry from a broad perspective and then narrow our scope by taking a closer look at the changes in the selected student newspapers across the country. This turned out to be a challenging task because of the large volume of literature on commercial newspapers and the difficulty to reach out to a more representative sample of student newspapers. Therefore, our sample consisted mainly of selected student newspapers in the U.S.

Since one of our endeavors was to learn the best practices and use them to inform ourselves on ways to move forward with our own student newspaper, our paper was oriented more on the practical side than the theoretical and methodological side in the research approach. As a result, the treatment of theoretical and methodological aspects was rather thin. This is the reason why our references were not as comprehensive as expected. Furthermore, this limitation also affects the generalizability of our results. Caution should be taken when applying the insights of this paper in another context.

Another limitation in our paper is its scope. In the discussion of the impact of digital transformation, we have left out many other relevant topics. For instance, we could not touch on a current important issue related to "fake news". With the transition of newspapers to become more digitized, "fake news" proliferation undoubtedly becomes a challenge that student newspapers must deal with. According a MIT research, "fake news" is found to travel six times as fast as regular news. Not only can they travel fast, but they can reach much farther, deeper, and more broadly than the truth in every category of information (Vosoughi, Roy, \& Aral, 2017).

The impact of "fake news" on student newspapers is certainly an urgent area for future research because today's students need to know how to discern between the "true" and the "fake news". Based 
on the yearlong study, commissioned by the Knight Foundation and published by Project Information Literacy, $36 \%$ of students said that the threat of "fake news" had made them distrust the credibility of any news. Reportedly, $45 \%$ of them lacked confidence with discerning real news from "fake news" (Callahan, 2018). Because of so much misinformation out there, students find it difficult to discern what is "real news" vs "fake news". One of potential negative impacts is that they may be antagonized at the "well-reported, well-researched, and well-sourced" news. Instead of trusting news that is based on the core principles of journalism: truth, independence, and accuracy, they may end up embracing "fake news" and being manipulated by "fake news". The threat of "fake news" may have a long-term effect on a generation of students (Callahan, 2018; Rayess, Chebl, Mhanna, \& Hage, 2018). What will these impacts be? How can students discern between "fake news" and "true news"? These are among many of the urgent questions that require further research in the future.

\section{REFERENCES}

Alt, R., \& Zimmermann, H. D. (2001). Preface: An introduction to special section-business models. Electronic markets, 11(1), 3-9. Routledge. https://doi.org/10.1080/10196780151105302

American Press Institute (API) (2006). Blueprint for transformation. Newspaper Next (N2): Transformation Project Report. American Press Institute. Retrieved from https://www.americanpressinstitute.org/wpcontent/uploads/2013/09/N2 Blueprint-for-Transformation.pdf

Amit, R., \& Zott, C. (2001). Value creation in e-business. Strategic Management Journal, 22(6-7), 493-520. https://doi.org/10.1002/smj.187

Ascarelli, M. (2014, July 24). For some college newspapers, it's not digital first. It's digital only. College Media Review: Journal of the College Media Association. Retrieved November 10, 2017, from http://cmreview.org/forsome-college-newspapers-its-not-digital-first-its-digital-only/

Boulton, C. (2018, December 11). What is digital transformation? A necessary disruption. CIO. Retrieved December 13, 2018, from https://www.cio.com/article/3211428/digital-transformation/what-is-digitaltransformation-a-necessary-disruption.html

Callahan, M. (2018, October 16). Faced with a daily barrage of news, college students find it hard to tell what's real and what's “fake news”.News@Northeastern. Retrieved December 10, 2018, from https://news.northeastern.edu/2018/10/16/faced-with-a-daily-barrage-of-news-college-students-find-ithard-to-tell-whats-real-and-whats-fake-news/

Cho, D., Smith, M. D., \& Zentner, A. (2016). Internet adoption and the survival of print newspapers: A country-level examination. Information Economics and Policy, 37, 13-19. https://doi.org/10.1016/j.infoecopol.2016.10.001

Dumpala, P. (2009, July 4). The year the newspaper died. Business Insider. Retrieved November 10, 2017, from http://www.Businessinsider.com/the-death-of-the-american-newspaper-2009-7/

Fetscherin, M., \& Knolmayer, G. (2004). Business models for content delivery: An empirical analysis of the newspaper and magazine industry. International Journal on Media Management, 6(1-2), 4-11. https://doi.org/10.1080/14241277.2004.9669377

Gimpel, G., \& Westerman, G. (2012). Shaping the future: Seven enduring principles for fast-changing industries. MIT Center for Digital Business. Retrieved from http://ebusiness.mit.edu/research/papers/2012.10 Gimpel Westerman Shaping\%20the\%20Future 299. pdf

Harvard Business School (HBS) (2015, September 13). The New York Times: Outwitted in the digital age? Digital Initiative (HBS). Digital Innovation \& Transformation: A Course at Harvard Business School. Retrieved December 10, 2018, from https://digit.hbs.org/submission/the-new-york-times-outwitted-in-thedigital-age/

Harvard Business School (HBS) (2018, February 1). Bezos, the digital Midas. Turning around the Washington Post. Digital Initiative (HBS). Digital Innovation \& Transformation: A Course at Harvard Business School. 
Retrieved December 10, 2018, from https://digit.hbs.org/submission/bezos-the-digital-midas-turningaround-the-washington-post/

Karimi, J., \& Walter, Z. (2015). The role of dynamic capabilities in responding to digital disruption: A factorbased study of the newspaper industry. Journal of Management Information Systems, 32(1), 39-81. https://doi.org/10.1080/07421222.2015.1029380

Kramer, M. (2016, August 30). What happened after 6 college newspapers cut their print schedules. Poynter. Retrieve November 10, 2017, from https://www.poynter.org/news/what-happened-after-6-collegenewspapers-cut-their-print-schedules/

Merriam, S. B. (1998). Qualitative research and case study applications in education. San Francisco, CA: Jossey-Bass.

Pew Research Center (2013, February 11). Newspapers turning ideas into dollars: Four revenue success stories. Pew Research Center Journalism \& Media Report. Retrieved November 10, 2017, from https://www.pewresearch.org/wpcontent/uploads/sites/8/legacy/NEWSPAPERREVENUEIDEAS.pdf

Rappa, M. (2001). Business models on the Web. Managing the Digital Enterprise. Retrieved March 1, 2018, from http://digitalenterprise.org/models/models.html

Rayess, M., Chebl, C., Mhanna, J., \& Hage, R. (2018). Fake news judgement: The case of undergraduate students at Notre Dame University-Louaize, Lebanon. Reference Services Review, 46(1), 146-149, https://doi.org/10.1108/RSR-07-2017-0027

Stake, R. E. (1995). The art of case study research. Thousand Oaks, CA: SAGE Publications.

Sweeney, S. (2015, December 1). Student newspapers struggle in a changing media environment. CommMedia Special Coverage. Pennsylvania State University: Donald P. Bellisario College of Communications. Retrieved November 10, 2017, from http://commmedia.psu.edu/special-coverage/story/best-ofcommedia/student-newspapers-struggle-in-a-changing-media-environment

Taylor, R. W., Fritsch, E. J., \& Liederbach, J. (2014). Digital crime and digital terrorism. New Jersey, United States: Prentice Hall Press.

Vosoughi, S., Roy, D., \& Aral S. (2017). The spread of true and false news online. MIT Initiative on the Digital Economy Research Brief. Retrieved December 10, 2018, from http://ide.mit.edu/sites/default/files/publications/2017\%20IDE $\% 20$ Research $\% 20 \mathrm{Brief} \% 20 \mathrm{False} \% 20 \mathrm{Ne}$ ws.pdf

Yazan, B. (2015). Three approaches to case study methods in education: Yin, Merriam, and Stake. The Qualitative Report, 20(2), 134-152. Retrieved December 10, 2018, from http://www.nova.edu/ssss/QR/QR20/2/yazan1.pdf

\section{BIOGRAPHIES}

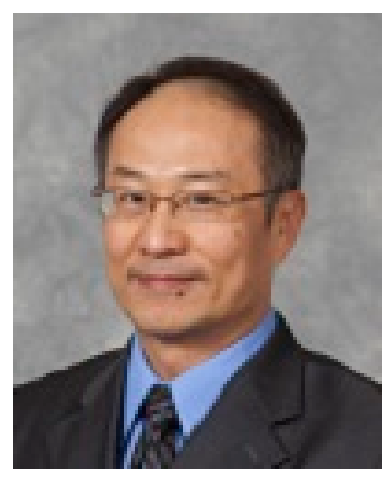

Minh Q. Huynh is an Associate Professor at Southeastern Louisiana University. He received his Ph.D. from State University of New York at Binghamton, and his B.S. in Computer Sciences from University of Maryland University College. His teaching interests are in the areas of Digital Marketing, Web design, Introduction to MIS. Research interests include software development using open source, web database implementation, web apps, technology supported distance education, IT for small businesses. His publications appear in journals such as the Journal of Information Technology Education: Innovations in Practice (JITE:IIP), the Communications of ACM, Journal of AIS, Communications of AIS, European Journal of IS, Journal of Electronic Commerce in Organizations, Journal of Information Systems Education, Business Studies Journal. 


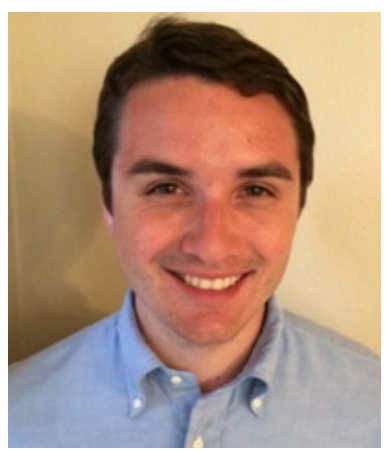

Nicholas Walsh is a Speech-Language Pathology Graduate Student at Southeastern Louisiana University, New Orleans, Louisiana. His goal is a concrete clinical and academic foundations in assessment and treatment of various speech and language disorders.

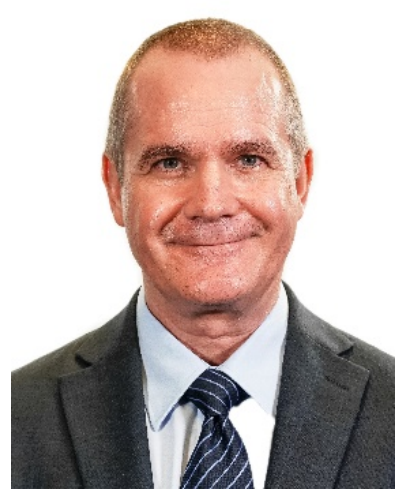

Scott McDonald is a Course Coordinator and Lecturer at RMIT University. He teaches into the Logistics \& Supply Chain Management as well as Tourism \& Hospitality Management programs. Dr. McDonald received his $\mathrm{PhD}$ in Business from Nottingham and his two Masters from Hertfordshire and Trinity College. His research interests are in Hospitality, Logistics, Communications, Alternative Therapies, Entrepreneurship, and Business Management. He is currently supervising two PhD candidates as well as leading three research projects focused on "Student Experience in Blended Learning", "Logistics Industry in Vietnam", and "Customer Experiences at 5-Star Hotels in Ho Chi Minh City" and is also a C.O.I.L. Coordinator for the School of Business \& Management at the Saigon campus of RMIT. 